\title{
Enzyme Activities in the Oral Fluids of Patients Suffering from Bulimia: A Controlled Clinical Trial
}

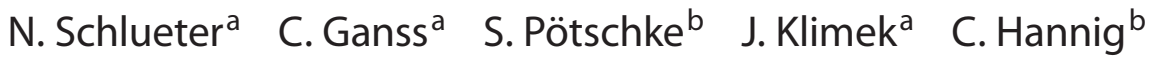 \\ a Department of Conservative and Preventive Dentistry, Dental Clinic, Justus Liebig University, Giessen, and \\ ${ }^{b}$ Clinic of Conservative Dentistry, Faculty of Medicine 'Carl Gustav Carus', Technical University of Dresden, \\ Dresden, Germany
}

\section{Key Words}

Bulimia $\cdot$ Clinical trial $\cdot$ Enzymes $\cdot$ Erosion $\cdot$ Protease $\cdot$ Saliva teases, collagenase and pepsin in resting and proteases in stimulated saliva were significantly higher in bulimic participants with erosion than in controls. Peroxidase activity was significantly decreased by regular vomiting. Proteolytic enzymes seem to be relevant for the initiation and progression of dental erosion directly after vomiting, maybe by both hydrolysis of demineralized dentine structures as well as modulation of the pellicle layer.

Copyright $\odot 2012$ S. Karger AG, Basel

Persons suffering from an eating disorder in combination with vomiting (bulimia nervosa) are at high risk for dental erosion, since gastricjuice is highly erosive [Bartlett and Coward, 2001]. However, not all bulimic patients show erosion, irrespective of the severity of their eating disorder [Robb et al., 1995], and it is still not clear, which factors are relevant for the development and progression of erosion in these patients. It is often speculated that differences in the composition of saliva are responsible for the rapidly progressing erosive substance loss in patients with vomiting-associated eating disorders [Frydrych et al., 2005].

In enamel, erosive demineralisation results in a continuous centripetal loss of dental substance [Lussi et al., 2011]. Several intraoral mechanisms protecting the den-

\section{KARGER \\ Fax +4161306 1234 \\ E-Mail karger@karger.ch}

www.karger.com (c) 2012 S. Karger AG, Basel

$0008-6568 / 12 / 0462-0130 \$ 38.00 / 0$

Accessible online at:

www.karger.com/cre
Dr. Nadine Schlueter

Dental Clinic, Department of Conservative and Preventive Dentistry

Schlangenzahl 14

DE-35392 Giessen (Germany)

Tel. +49641994 6173, E-Mail nadine.schlueter@ dentist.med.uni-giessen.de 
tal hard tissue against mechanical and chemical impacts are discussed. A very important one is pellicle formation [Hara et al., 2006; Joiner et al., 2008]. It is regarded as a barrier and buffer against erosive noxae but it is fairly permeable to water and certain ions [Hannig and Balz, 2001; Hannig et al., 2007; Joiner et al., 2008]. Acids reduce pellicle thickness and therewith its protective effect in a time- and $\mathrm{pH}$-dependent manner [Hannig and Balz, 2001], finally resulting in a partial destruction of the pellicle [Nekrashevych et al., 2004] and higher loss of mineral from the underlying enamel [Hannig et al., 2004b]. In dentine other factors also play a role due to differences in histological structure. In contrast to enamel, dentine contains high amounts of organic material, mainly collagen type I and V, but also non-collagenous proteins such as dentine phosphoproteins, dentine sialoproteins, and dentine matrix proteins, proteoglycans and phospholipids [Garant, 2003]. In case of erosive demineralization, the organic structures will be exposed. However, clinically relevant acidic impacts are not capable of removing this organic matrix. Therefore, the organic fraction persists on the surface, at least in vitro, whilst erosive mineral loss continues [Ganss et al., 2009; Lussi et al., 2011]. Under in vitro conditions, erosion progression can be accelerated by partial [Schlueter et al., 2010] or complete [Ganss et al., 2010] enzymatic removal of the organic matrix. Therefore, two factors probably play a role for the specific erosion progression in dentine: firstly, the presence of the organic matrix and, secondly, the protective properties of the acquired pellicle. Both the matrix and the pellicle could possibly be altered by proteolytic enzymes. Accordingly, it can be hypothesized that the activities of certain enzymes in the saliva are relevant for erosion progression, both in enamel and dentine.

Enzymes of potential importance are proteases specific for collagen, such as matrix metalloproteases (MMPs) [Davis, 1991; Mäkelä et al., 1994; Ingman et al., 1996; DenBesten et al., 1998; Apajalathi et al., 2003; van Strijp et al., 2003]. In the context of erosion MMP-1 and -8 (collagenases), and MMP-2 and -9 (gelatinases) could be of major importance, as these isoforms are resistant to acids and, moreover, are activated by a decrease in $\mathrm{pH}$ [Davis, 1991; Tjäderhane et al., 1998; Vuotila et al., 2002] with a subsequent increase in $\mathrm{pH}$ to neutral values [Davis, 1991]. Inactive precursors of these MMPs have been detected in the saliva [Davis, 1991; Mäkelä et al., 1994] or gingival crevicular fluid [Apajalathi et al., 2003] of healthy subjects. Regarding pathological conditions, the impact of MMPs on the organic matrix during degradation of collagen fibres in dentine caries [Tjäderhane et al., 1998; van Strijp et al., 2003] and changes in activity during the development and progression of inflammatory processes like periodontitis have been shown [Mäkelä et al., 1994; Sorsa et al., 2004]. Especially with respect to the activation mechanism, MMPs could also be relevant for the pathological mechanism of erosion.

Various non-specific enzymes could also play a role. Under erosive in vitro conditions, pepsin can partially degrade the demineralized organic matrix [Schlueter et al., 2007] and the combination of pepsin and trypsin can enhance erosive mineral loss [Schlueter et al., 2010]. Pepsin is detectable in the saliva during reflux episodes [Kim et al., 2008]. Therefore, it is possible that pepsin is also present in the oral cavity after vomiting. There are no studies on the presence of trypsin in the oral cavity, a digestive enzyme from the duodenum, though its presence after extensive vomiting is not unlikely.

Only little is known about the enzyme activities in the oral fluids of patients with bulimia, in particular directly after vomiting. However, the activities of various proteolytic enzymes and of key enzymes, like amylase, lysozyme and peroxidase, which mirror the biological activity of saliva [Hannig et al., 2005], might be altered directly by vomiting or indirectly by pathological changes of the salivary glands due to frequent vomiting.

Thus, various factors could potentially modulate erosion progression. The aim of the present study was, therefore, to analyse different salivary parameters of persons diagnosed with bulimia nervosa with and without signs of dental erosion in comparison with healthy controls. Parameters under investigation were flow rate, $\mathrm{pH}$ and buffering capacity as the basic parameters and the activities of various enzymes (proteases in general, collagenase, pepsin and trypsin as well as amylase, peroxidase and lysozyme). The null hypothesis was that there are no differences between the groups.

\section{Methods}

\section{Participants}

The clinical part of the study was conducted at the Department of Conservative and Preventive Dentistry in the dental clinic of Justus Liebig University of Giessen. The enzyme assays were performed in the Clinic of Conservative Dentistry, Faculty of Medicine 'Carl Gustav Carus', Technical University of Dresden. The study conformed to the Declaration of Helsinki and was performed according to the guidelines of Good Clinical Practice. It was approved by the ethics committee of the University of Giessen (EthikKommission des Fachbereiches Medizin, application No. 114/08).

The trial was planned as a prospective controlled clinical study. A total of 28 volunteers were included: 14 healthy subjects 
without any signs of erosion (control group) and 14 subjects diagnosed with bulimia nervosa (code F50.2 according to ICD 10) and a vomiting frequency of at least once per day. Two subgroups of patients with bulimia (both $n=7$ ) were analysed: bulimic patients showing no signs of enamel or dentine erosion (bulimia without erosion) and bulimic patients having erosive defects (bulimia with erosion), diagnosed according to the criteria described earlier [Ganss and Lussi, 2006; Lussi and Jaeggi, 2008]. In all patients defects reached the dentine. The control group was matched according to age and gender. Inclusion criteria were age of consent and informed written consent. Exclusion criteria were carious lesions, insufficient fillings, periodontitis, serious diseases except for bulimia nervosa, and medication affecting salivation.

\section{Procedure, Evaluation Criteria, and Responsibilities}

Collection of Saliva

From all participants, resting and stimulated saliva was analysed; additionally, from bulimic patients, saliva collected directly and $30 \mathrm{~min}$ after vomiting was investigated. All clinical procedures were performed by one investigator.

The saliva was collected according to the recommendations of Birkhed and Heintze [1989]. All samples of resting and stimulated saliva were collected in the dental clinic between 02.00 and 03.00 p.m., to minimize circadian variations. All participants were asked to abstain from food intake for at least $2 \mathrm{~h}$ prior to saliva collection. Resting saliva was collected over a period of $5 \mathrm{~min}$. Directly afterwards, saliva was stimulated by chewing a piece of paraffin and was collected over a period of $2 \mathrm{~min}$. Directly after collecting, saliva was frozen for $48 \mathrm{~h}$ at $-20^{\circ} \mathrm{C}$ and after the 48 -hour period at $-80^{\circ} \mathrm{C}$ until analysis. Participants suffering from bulimia nervosa were asked to collect saliva at home directly and $30 \mathrm{~min}$ after vomiting corresponding to the collection of resting saliva over a period of $5 \mathrm{~min}$. All bulimic participants were intensively trained in collecting saliva. Saliva samples were frozen by the volunteers directly after the collection at $-20^{\circ} \mathrm{C}$. Samples were fetched by the investigator within $48 \mathrm{~h}$ and stored at $-80^{\circ} \mathrm{C}$ until analysis.

\section{Analysis of Saliva}

Analysis of the saliva was performed in a blinded manner. Flow rate, $\mathrm{pH}$ and buffering capacity were analysed in Giessen, enzymatic assays were carried out in Dresden.

Flow Rate, $\mathrm{pH}$ and Buffering Capacity. Flow rate was quantified by weighing; $\mathrm{pH}$ was measured with an ion-selective electrode (InLab micro pH electrode 423, Mettler Toledo, Giessen, Germany; 520A pH meter, ORION Research Inc., Boston, Mass., USA). For analysis of buffering capacity $1 \mathrm{ml}$ of saliva was mixed with $3 \mathrm{ml} \mathrm{HCl}$ ( $5 \mathrm{mM}$, Merck, Darmstadt, Germany) for $10 \mathrm{~min}$. After incubation for $10 \mathrm{~min}, \mathrm{pH}$ was measured with an ion-selective electrode [Birkhed and Heintze, 1989; Ganss and Lussi, 2006].

Enzymatic Assays. Enzymatic assays were carried out with a Tecan Infinite M 200 micro-plate reader (Tecan, Crailsheim, Germany). All enzymatic assays were performed with non-centrifuged and centrifuged saliva $\left(4^{\circ} \mathrm{C}, 10 \mathrm{~min}, 6,000 \mathrm{rpm}\right)$.

Protease. General protease activity was measured with a test kit (EnzChek protease assay kit, E 6638, Molecular Probes, Leiden, The Netherlands). Derivatives of casein were labelled with fluorogenic BODIPY. In case of hydrolysis, fluorescent peptides released can be measured directly. The assay was carried out at a $\mathrm{pH}$ of 7.8 (10 mM Tris- $\left.\mathrm{HCl}, 0.1 \mathrm{mM} \mathrm{NaN}_{3}\right)$.
Collagenase/Gelatinase. Collagenase activity was measured using a commercially available test kit (EnzyChek gelatinase/collagenase assay, Molecular Probes). It is based on the specific hydrolysis of a DQ fluorogenic gelatin fluorescein conjugate in reaction buffer ( $\mathrm{pH}$ 7.5, $0.05 \mathrm{M}$ Tris- $\mathrm{HCl}, 0.15 \mathrm{M} \mathrm{NaCl}, 5 \mathrm{mM} \mathrm{CaCl}_{2}$, $0.2 \mathrm{nM} \mathrm{NaN}_{3}$ ).

Pepsin. Pepsin was measured with the EnzChek protease assay kit (E 6638, Molecular Probes) at pH 2 (10 mM Tris-HCl, $0.1 \mathrm{mM}$ $\mathrm{NaN}_{3}$.

Trypsin. Trypsin activity was determined using the specific substrate N-benzoyl-D, L-arginin- $p$-nitroanilide. It is cleaved specifically by trypsin, the product $p$-nitroanilin can be determined photometrically at a wavelength of $410 \mathrm{~nm}$ [Gonçalves et al., 2007]. The buffer used was $50 \mathrm{~mm}$ phosphate buffer ( $\mathrm{pH} 7.0$, $25 \mathrm{mM} \mathrm{KH}_{2} \mathrm{PO} 4,25 \mathrm{mM} \mathrm{Na}_{2} \mathrm{HPO}_{4}$ ).

Amylase. Amylase activity was measured with the low molecular weight substrate 2-chloro-4-nitrophenyl-4-O-beta-D-galactopyranosylmaltotriosid (GalG2CNP) as described previously [Morishita et al., 2000; Hannig et al., 2004a]. GalG2CNP has been shown to be hydrolysed directly by salivary amylase without any auxiliary enzyme yielding the free aglycone 2-chloro-4-nitrophenolate (CNP) [Morishita et al., 2000]. For determination of salivary amylase activity, $10 \mu \mathrm{l}$ of saliva was diluted 1:100 in MES buffer [0.05 M MES (2-N-morpholino-ethanesulfonic acid), $0.03 \%$ $\mathrm{NaN}_{3}, 0.03 \%$ albumin]. Ten microlitres of the diluted sample was pipetted to $90 \mu \mathrm{l}$ MES buffer and admixed to $200 \mu \mathrm{l}$ of a standard incubation test solution. The amylase test solution consisted of $5 \mathrm{mM}$ GalG2CNP, $5 \mathrm{mM} \mathrm{CaCl}_{2}, 50 \mathrm{~mm} \mathrm{NaSCN}, 0.03 \%$ albumin and $0.03 \% \mathrm{NaN}_{3}$ in $50 \mathrm{mM}$ MES buffer ( $\mathrm{pH}$ 6.0). Extinction was read at $405 \mathrm{~nm}$ at $25^{\circ} \mathrm{C}$.

Peroxidase. Peroxidase activity was determined as described in detail previously [Proctor and Chan, 1994; Hannig et al., $2008 \mathrm{~b}$ ]. In the presence of peroxidase and hydrogen peroxide, fluorogenic $2^{\prime}, 7^{\prime}$-dichlorofluorescein (LDCF) is converted to fluorescent dichlorofluorescein (DCF). Stock solutions of the stable reagent $2^{\prime}, 7^{\prime}$-dichlorofluorescein diacetate (LDADCF) were stored at $-80^{\circ} \mathrm{C}\left(5 \times 10^{-5} \mathrm{M}\right.$ in absolute ethanol). The fluorogenic substrate LDCF was prepared freshly every day from LDADCF. One part of LDADCF solution was admixed to 9 parts of $0.01 \mathrm{M}$ sodium hydroxide, and incubated for $30 \mathrm{~min}$. The reaction was stopped by addition of phosphate buffer $(0.15 \mathrm{M}, \mathrm{pH} 6)$. For determination of peroxidase activity in the saliva samples, $4 \mu$ l were added to $200 \mu \mathrm{l}$ test buffer $(0.15 \mathrm{M}, 1 \mathrm{mM} \mathrm{KSCN}, \mathrm{pH}$ 6) and incubated for $10 \mathrm{~min}$ at $37^{\circ} \mathrm{C}$. In the following, $20 \mu \mathrm{l}$ of $2.2 \mathrm{~mm}$ hydrogen peroxide solution and $20 \mu \mathrm{l}$ of the LDCF reagent were added. The fluorescence of DCF was recorded at an excitation of $\lambda=$ $488 \mathrm{~nm}$ and an emission of $\lambda=530 \mathrm{~nm}$. One unit of peroxidase activity was defined as $1 \mathrm{~mm}$ DCF released per minute.

Lysozyme. The assay measures lysozyme activity via hydrolysis of fluorescein-labelled Micrococcus lysodeicticus (EnzCheck Lysozyme assay kit; E-22013, Molecular Probes) [Maeda, 1980; Vray et al., 1980; Hannig et al., 2009]. Substrate solution and buffer were prepared according to the manufacturer's instructions. The composition of the test buffer is $0.1 \mathrm{M}$ sodium phosphate, $0.1 \mathrm{M} \mathrm{NaCl}$ and $2 \mathrm{mM}$ sodium azide ( $\mathrm{pH} 7.5$ ). The excitation was $\lambda=494 \mathrm{~nm}$, the emission was recorded at $\lambda=518 \mathrm{~nm}$. Saliva samples were diluted 1:10 with buffer solution, $50 \mu$ l were added to $50 \mu \mathrm{l}$ substrate solution and the emission was recorded continuously over a 10 -min period. 
Table 1. Flow rate, $\mathrm{pH}$ and buffering capacity of all groups (mean $\pm \mathrm{SD}$ ) and the respective norm values

\begin{tabular}{llll}
\hline $\begin{array}{l}\text { Group/ } \\
\text { Saliva }\end{array}$ & Flow rate & $\mathrm{pH}$ & $\begin{array}{l}\text { Buffering } \\
\text { capacity }\end{array}$ \\
\hline $\begin{array}{l}\text { Control } \\
\text { Resting }\end{array}$ & $0.56 \pm 0.25^{\mathrm{a}, \mathrm{A}}$ & $7.07 \pm 0.44^{\mathrm{a}, \mathrm{A}}$ & $6.34 \pm 0.62^{\mathrm{a}, \mathrm{A}}$ \\
Stimulated & $1.86 \pm 0.86^{\mathrm{a}, \mathrm{B}}$ & $7.53 \pm 0.32^{\mathrm{a}, \mathrm{B}}$ & $6.92 \pm 0.56^{\mathrm{a}, \mathrm{B}}$ \\
\hline Bulimia and erosion & & \\
Resting & $0.35 \pm 0.18^{\mathrm{a}, \mathrm{A}}$ & $6.87 \pm 0.21^{\mathrm{a}, \mathrm{A}}$ & $6.03 \pm 0.72^{\mathrm{a}, \mathrm{A}, \mathrm{B}}$ \\
Stimulated & $1.86 \pm 1.02^{\mathrm{a}, \mathrm{B}}$ & $7.89 \pm 0.52^{\mathrm{a}, \mathrm{b}, \mathrm{A}}$ & $6.98 \pm 0.29^{\mathrm{a}, \mathrm{A}}$ \\
Directly & $0.80 \pm 0.41^{\mathrm{a}, \mathrm{A}, \mathrm{B}}$ & $7.90 \pm 0.83^{\mathrm{a}, \mathrm{A}}$ & $6.54 \pm 0.69^{\mathrm{a}, \mathrm{A}, \mathrm{B}}$ \\
30 min & $0.65 \pm 0.37^{\mathrm{a}, \mathrm{A}, \mathrm{B}}$ & $6.71 \pm 0.69^{\mathrm{a}, \mathrm{A}}$ & $5.69 \pm 0.47^{\mathrm{a}, \mathrm{B}}$ \\
\hline Bulimia, no erosion & & \\
Resting & $0.36 \pm 0.19^{\mathrm{a}, \mathrm{A}}$ & $6.79 \pm 0.33^{\mathrm{a}, \mathrm{A}, \mathrm{C}}$ & $5.79 \pm 0.49^{\mathrm{a}, \mathrm{A}, \mathrm{C}}$ \\
Stimulated & $2.03 \pm 1.35^{\mathrm{a}, \mathrm{A}}$ & $8.20 \pm 0.67^{\mathrm{b}, \mathrm{B}, \mathrm{D}}$ & $7.06 \pm 0.41^{\mathrm{a}, \mathrm{B}}$ \\
Directly & $0.80 \pm 0.44^{\mathrm{a}, \mathrm{A}}$ & $8.81 \pm 0.84^{\mathrm{a}, \mathrm{B}, \mathrm{C}}$ & $7.53 \pm 0.48^{\mathrm{b}, \mathrm{A}, \mathrm{B}, \mathrm{C}}$ \\
30 min & $0.57 \pm 0.27^{\mathrm{a}, \mathrm{A}}$ & $7.00 \pm 0.69^{\mathrm{a}, \mathrm{A}, \mathrm{D}}$ & $5.82 \pm 0.82^{\mathrm{a}, \mathrm{C}}$ \\
\hline $\begin{array}{l}\text { Norm values } \\
\text { Resting }\end{array}$ & $>0.25$ & $>6.5$ & $>4.75$ \\
Stimulated & $>1.00$ & $>7.0$ & $>5.75$ \\
\hline
\end{tabular}

Statistical significance between groups within one type of saliva is indicated by different lower-case letters, statistical significance between types of saliva within one group is indicated by different upper-case letters.

\section{Statistical Analysis}

All statistical procedures were performed with IBM SPSS Statistics 19.0 (Armonk, N.Y., USA). Data were tested for deviation from the Gaussian distribution with the Kolmogorov-Smirnov test. Differences between groups (control, bulimia with erosion, bulimia without erosion) were compared with a one-way ANOVA followed by Tukey's post hoc test. The level of significance was 0.05 .

For comparison of various types of saliva (resting saliva, stimulated saliva, saliva collected directly and 30 min after vomiting) within one group, t-test with Bonferroni adjustment were performed. The level of significance after Bonferroni adjustment was 0.008 .

\section{Results}

Mean age of all participants was $27.1 \pm 5.6$. Mean vomiting frequency per day was $2.1 \pm 2.7$ (maximum 6.5 \pm 3.8 , mean duration of disease $12.9 \pm 6.5$ years) in the bulimia with erosion group and $2.5 \pm 3.2$ (maximum 5.0 \pm 3.2 , mean duration of disease $7.1 \pm 3.3$ years) in the bulimia without erosion group (all differences NS). One participant in the bulimia with erosion group and 1 participant in the bulimia without erosion group received bulimia-related pharmacotherapy (selective serotonin reuptake inhibitors; bulimia with erosion: venlafaxine; bulimia without erosion: fluoxetine). All other participants took no medicine with impact on saliva. All saliva samples were evaluable, except for 1 participant from the bulimia without erosion group. From this participant, the samples directly and $30 \mathrm{~min}$ after vomiting were missing.

\section{Flow Rate, pH, Buffering Capacity}

There were only small differences between the groups for the basic parameters flow rate, $\mathrm{pH}$ and buffering capacity (table 1). Buffering capacity directly after vomiting was lower in the bulimia with erosion group than in the group without erosion ( $p \leq 0.01$ ). A similar tendency was found for $\mathrm{pH}$ in this type of saliva, but this difference failed significance $(\mathrm{p}=0.075)$. $\mathrm{pH}$ of stimulated saliva in the bulimia without erosion group was significantly higher than in the control group ( $\mathrm{p} \leq 0.05$ ).

Comparison of the results within one group showed that in the control group values of all parameters obtained from stimulated saliva were significantly higher than those of resting saliva ( $\mathrm{p} \leq 0.008$ ). In the bulimic groups, the increase in $\mathrm{pH}$, buffering capacity and flow rate from resting to stimulated saliva was comparable to the control group, though not reaching significance in each case. For $\mathrm{pH}$ and buffering capacity, but not for flow rate, the values directly after vomiting ( $30 \mathrm{~min}$ after vomiting) were comparable to those of stimulated (resting) saliva.

\section{Enzyme Assays - Non-Centrifuged Saliva}

Differences in enzyme activities (fig. 1,2) were more distinct than for the basic parameters. In particular, within the proteolytic enzymes clear differences between healthy subjects (control group) and bulimic participants with erosion (bulimia with erosion group) were found.

Higher enzyme activities were measured for general proteolytic activity (protease, increase of 306\%, p $\leq$ 0.05 ), collagenase (increase of $99 \%, p \leq 0.05$ ), and pepsin (increase of $95 \%, \mathrm{p} \leq 0.05$ ) in resting saliva and for general proteolytic activity (protease, increase of $303 \%, \mathrm{p} \leq$ 0.001 ) in stimulated saliva in the bulimia with erosion group than in the control group. Regarding the remaining enzymes, no significant differences were found for amylase and lysozyme. Peroxidase activity was significantly lower in participants suffering from bulimia nervosa, irrespective of the presence of erosion (resting saliva: control vs. bulimia with erosion $85 \%$ reduction, $\mathrm{p} \leq$ 0.001 ; control vs. bulimia without erosion $71 \%$ reduction, $\mathrm{p} \leq 0.01$; stimulated saliva: control vs. bulimia with ero- 


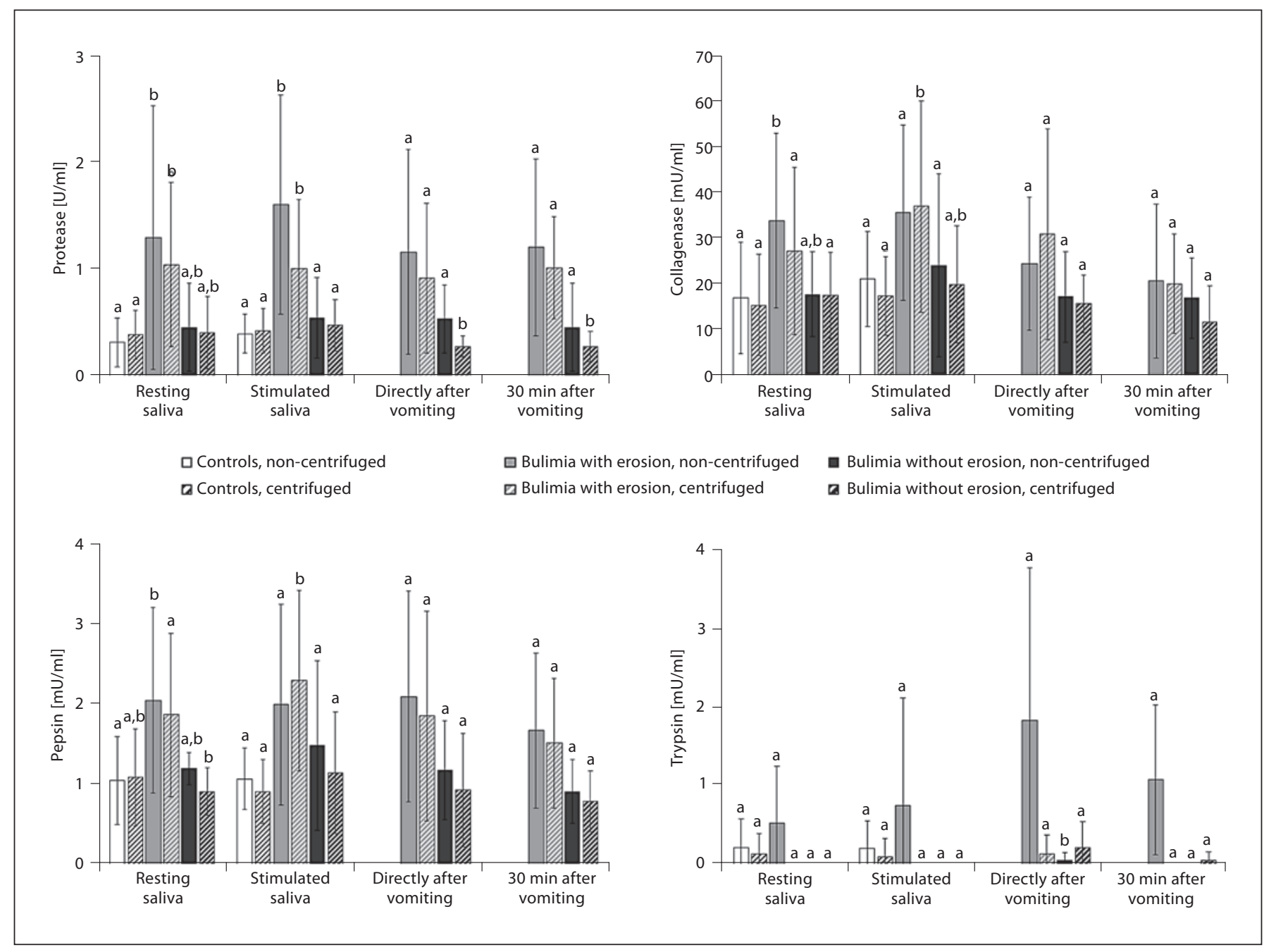

Fig. 1. Results of enzyme assays (mean $\pm \mathrm{SD}$ ) for general proteolytic activity (protease), collagenase, pepsin and trypsin in non-centrifuged and centrifuged saliva in all types of saliva (resting, stimulated, directly after vomiting and $30 \mathrm{~min}$ after vomiting) from all groups (control group, bulimic patients with erosion, bulimic patients without erosion). Statistics were performed separately for centrifuged and non-centrifuged saliva. Statistical significance between groups within one type of saliva is indicated by different lower-case letters. No difference between types of saliva within one group was found.

sion $88 \%$ reduction, $\mathrm{p} \leq 0.001$; control vs. bulimia without erosion $83 \%$ reduction, $\mathrm{p} \leq 0.001$ ). No difference was found between both bulimic groups (NS).

Changes in activity within one group between various types of saliva were only found for lysozyme. In the bulimia with erosion group, lysozyme activity was significantly lower in saliva directly after vomiting than in resting saliva (56\% reduction) and $30 \mathrm{~min}$ after vomiting (61\% reduction); in the bulimia without erosion group saliva directly after vomiting showed a lower lysozyme activity (59\% reduction) than resting saliva (all $\mathrm{p} \leq 0.008$ ).

\section{Enzyme Assays - Centrifuged Saliva}

Basically, results were the same as in non-centrifuged saliva. For general proteolytic activity, higher activities were found in the bulimia with erosion group than in the control group in resting (increase of $169 \%, \mathrm{p} \leq 0.05$ ) and stimulated saliva (increase of $135 \%, \mathrm{p} \leq 0.05$ ). The general proteolytic activity in stimulated saliva was also higher in the bulimia with erosion group than in the bulimia without erosion group (increase of $156 \%, \mathrm{p} \leq 0.05$ ) and in saliva collected directly (increase of $229 \%, \mathrm{p} \leq 0.05$ ) as well as $30 \mathrm{~min}$ after vomiting (increase of $264 \%, \mathrm{p} \leq 0.01$ ). 


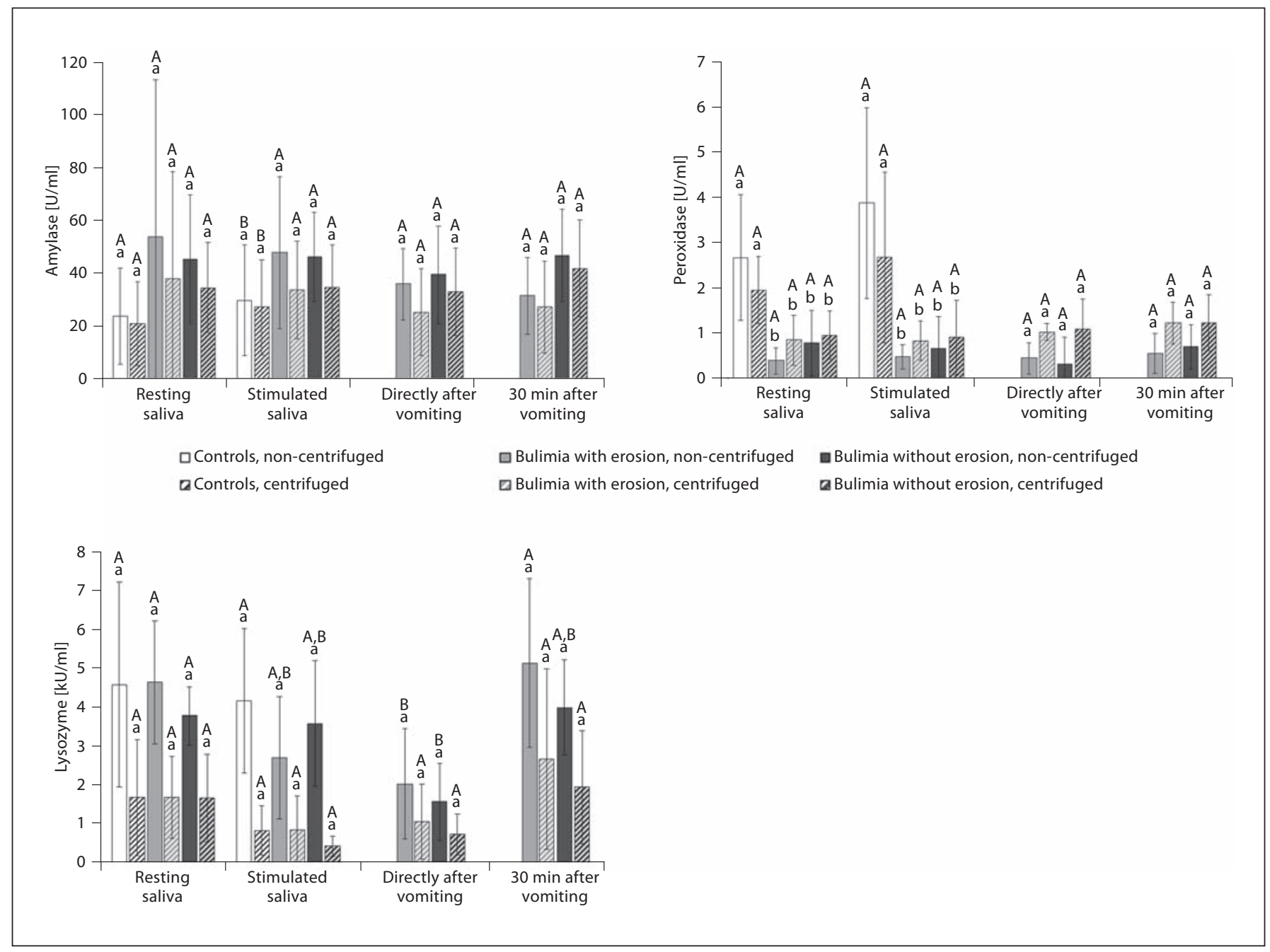

Fig. 2. Results of the enzyme assays (mean $\pm \mathrm{SD}$ ) for general amylase, peroxidase and lysozyme in non-centrifuged and centrifuged saliva in all types of saliva (resting, stimulated, directly after vomiting and 30 min after vomiting) from all groups (controls, bulimic patients with erosion, bulimic patients without erosion). Statistics were performed separately for centrifuged and non-centrifuged saliva. Statistical significance between groups within one type of saliva is indicated by different lower-case letters, statistical significance between types of saliva within one group is indicated by different upper-case letters.

In the bulimia with erosion group, pepsin and collagenase activities were increased in stimulated saliva (pepsin: increase of $153 \%, \mathrm{p} \leq 0.001$; collagenase: increase of $112 \%, \mathrm{p} \leq 0.05$ ) as compared with the control group. Pepsin activity was also higher in patients with erosion than in patients without erosion, both in resting (increase of $105 \%, \mathrm{p} \leq 0.05$ ) and stimulated saliva (increase of $100 \%, \mathrm{p} \leq 0.05)$. For trypsin, amylase and lysozyme no differences were found at all. Peroxidase activity was significantly reduced by vomiting both in resting $(57 \%$ reduction, $\mathrm{p} \leq 0.05)$ and stimulated saliva $(69 \%$ reduction, $\mathrm{p} \leq 0.05)$. No significant differences were found between the various types of saliva within one group (fig. 1,2).

\section{Discussion}

This study investigated the activity of various proteolytic enzymes in the saliva of patients suffering from bulimia nervosa in comparison to a healthy control group not only in resting and stimulated saliva, but for the first 
time also in saliva collected directly and $30 \mathrm{~min}$ after vomiting. In particular, the latter two types are of special interest, since it was hypothesized that differences in these oral fluids could explain the variabillity in dental erosion in patients with bulimia nervosa. In order to allow comparison with data from the literature and to gain information on the basic functional properties of saliva [Hannig et al., 2005], activities of amylase, lysozyme and peroxidase have also been analysed. Both centrifuged and non-centrifuged saliva samples were analysed to identify different sources of enzyme activity (e.g. bacterial, salivary, cellular). However, only few differences between the two types of saliva were found.

Only volunteers with a professional diagnosis of bulimia were included. The definition of bulimia is 'a syndrome characterized by repeated bouts of overeating and an excessive preoccupation with the control of body weight, leading to a pattern of overeating followed by vomiting or use of purgatives' (ICD-10). As the intention of the study was to investigate the impact of vomiting, only bulimic patients with regular vomiting episodes (vomiting frequency of at least once per day) were included. Both normal-weight and slightly underweight patients, but no anorectic patients participated. Mean vomiting frequency was nearly the same in both bulimic groups (NS). The mean duration of the disease was longer in the bulimia group with erosion than in the bulimia group without erosion. However, this difference was not significant and it is conceivable that over a 7-year period of regular vomiting with a mean vomiting frequency of 2.5 per day and a maximum frequency of 5.0 per day, manifest erosive defects can occur.

The most relevant finding of the present study is the enhanced proteolytic activity in the oral fluids of bulimia patients with erosion as compared with controls or bulimia patients showing no erosion. To the best of our knowledge this has not been shown until now. Several sources may contribute to the general proteolytic activity in the oral cavity. Besides the secretion of saliva by the salivary glands or the gingival crevicular fluid, also bacterial enzymes and secretions from the oesophageal and oral mucosa have to be taken into consideration. Furthermore, certain components of the gastrointestinal fluids might reach the oral cavity during regurgitation such as pepsin or trypsin.

One co-factor of dentine erosion, at least in vitro, is the proteolytic degradation of the exposed collagen fibres after acid-induced loss of hydroxyapatite [Kleter et al., 1994; Ganss et al., 2004; Schlueter et al., 2010]. Specific enzymes, like MMPs, may contribute to this process [Zheng et al., 2011]. Indeed, collagenase activity was found to be enhanced in the group of bulimia patients with erosion. Precursors of collagenase are secreted by the salivary glands activated by a decrease in pH [Davis, 1991; Mäkelä et al., 1994]. Possible sources for MMPs are the oral fluids, saliva and gingival sulcus fluid, as well as the dentine itself [Moon et al., 2010]. It is possible that adaption processes in the parotid gland of some subjects might enhance the release of salivary collagenase. MMPs play also an important role in normal duodenal digestion [Davis, 1991]. On the one hand, they are swallowed together with the saliva [Davis, 1991], on the other hand they are synthesized by the parietal cells of the stomach [Tatsuguchi et al., 1999]. Therefore, the gastric content itself is probably an additional source for collagenase, which retrogradely reaches the oral cavity during extensive vomiting.

The present data indicated proteolytic activity of oral fluids at low $\mathrm{pH}$. Thereby, saliva of bulimic patients with erosion yielded higher proteolytic activity than that of the other two groups. Pepsin activity was measured with a protease kit at a low $\mathrm{pH}(\mathrm{pH} 2)$, and even if pepsin is the most common proteolytic enzyme with a measurable activity at this $\mathrm{pH}$, other proteolytic enzymes should also be considered, such as cathepsin from the oral fluids [Nascimento et al., 2011], gastricsin from the stomach [Richter et al., 1998] or acid-resistant proteases from some bacterial strains, respectively.

Furthermore, trypsin-like activity was detected even in the oral fluids of controls without eating disorders. This does not necessarily mean that there is trypsin in the saliva of healthy patients but trypsin-like activity. Trypsin-like enzymes can be found in the submandibular gland [Furuyama et al., 1987] and in normal gingival tissue [Uitto, 1987]. Accordingly, slight trypsin-like activity was not an unexpected finding in the saliva of healthy subjects. Interestingly, there was, although not statistically significant, higher trypsin-like activity in the saliva of bulimia patients with erosion, especially after regurgitation, indicating that trypsin from the duodenum reached the oral cavity. It seems to be immobilized or at least accumulated with high tenacity in the oral cavity. Trypsin interacts with several other enzymes and can, for example, contribute to the activation of MMPs in vitro [Lindstad et al., 2005] and to pathological processes in vivo [Descamps et al., 2004; Vilen et al., 2008]. Therefore, intraoral trypsin in patients with bulimia and erosion could possibly also enhance the activity of oral MMPs, which in turn can intensify the possible proteolysis of the dentine matrix or the pellicle layer. 
All in all the observed enhanced proteolytic enzyme activities in the saliva of patients suffering from severe erosions are in good accordance with previous in vitro experiments showing the promoting effect of certain enzymes on the progression of dentine erosion due to degradation of the demineralized organic dentine matrix [Kleter et al., 1994; Ganss et al., 2004; Schlueter et al., 2010].

Besides their impact on the organic matrix, proteolytic enzymes may also impair the tenacity and the protective properties of the acquired pellicle against acidic noxae. It is known that the protective properties of the pellicle are limited and that the thickness of the pellicle is decreased during erosive attacks [Hannig and Balz, 2001; Hara et al., 2006; Hannig et al., 2007; Joiner et al., 2008]. Proteases and peptidases in the oral fluids are considered relevant for the extrinsic maturation and proteolysis of pellicle components even if the pellicle itself contains nearly no proteolytic activity [Hannig et al., 2005, 2008c]. Therefore, it is quite possible that changes in the activities of oral proteolytic enzymes in patients with eating disorders may have considerable impact on the protective properties of the pellicle. Some of the bulimic patients even had no signs of erosion though suffering considerably from eating disorders over years. Accordingly, it might be hypothesized that their pellicles have better protective properties, probably due to less hydrolysis of pellicle components by proteolytic enzymes, which on the one hand can enhance the permeability of this layer [Hannig and Joiner, 2006; Hannig et al., 2008c], but on the other hand might retard pellicle formation and reconstitution after erosive attacks.

Regarding the remaining three enzymes amylase, peroxidase and lysozyme, significant differences between the three groups were only found for peroxidase activity, which was clearly reduced in patients with regular vomiting. In contrast to other enzymes salivary peroxidase is inactivated by its substrate and several other metabolites [Hannig et al., 2008a, b]. Due to enhanced oxidative stress in the oral cavity of subjects with bulimia, induced by gastric juice, it was to be expected that peroxidase is inactivated.

For the other two enzymes only tendencies towards activity changes were found, which reached no significance, maybe due to the relatively small number of cases. Amylase is the most abundant enzyme in the oral fluid and the most frequent protein in parotid secretion [Veerman et al., 1996; Sas and Dawes, 1997]. Amylase activity tended to be higher in all patients with bulimia than in the control group. This is in clear concordance with the literature, showing a higher salivary amylase level in bulimic patients, particularly in patients suffering from bulimia-related reactive parotid swelling [Scheutzel and Gerlach, 1991].

Regarding lysozyme activity, only differences were found between the various types of saliva within one group but not between different groups of subjects. Typically, lysozyme, mainly secreted by the submandibular and sublingual glands, is reduced in stimulated saliva [Stuchell and Mandel, 1983; Veerman et al., 1996]. This was also recorded in the present study for all groups. However, this was not only found for stimulated saliva, but also for saliva collected directly after vomiting. Hence, vomiting can be regarded as a strong stimulus for the secretion of saliva from the parotid glands. Nevertheless, the findings for lysozyme indicate a physiological function of resting and stimulated saliva in patients with bulimia and no considerable adaptive effects on salivary glands induced by chronic vomiting.

It has been speculated that the basic salivary parameters such as flow rate, $\mathrm{pH}$ and buffering capacity are modified by regular vomiting [Frydrych et al., 2005]. In contrast, the present study has clearly shown that, except for flow rate of resting saliva, none of them was pathologically altered. Bulimia per se reduced the flow rate of resting saliva in patients suffering from bulimia significantly $(\mathrm{p} \leq 0.05)$ irrespective of the presence of erosions (NS between both bulimic groups). Additionally, there were no changes in basic parameters indicating a reduced function of the saliva directly and $30 \mathrm{~min}$ after vomiting in bulimic patients. The sole difference in basic salivary parameters was found between both bulimic groups in buffering capacity directly after vomiting. This was significantly lower in patients with bulimia and erosion than in patients with bulimia without erosion. However, it is not clear whether this difference is a predisposing factor for the formation of erosion in these patients. The buffering capacity is regulated by three different buffer systems, the phosphate [Birkhed and Heintze, 1989], the carbonate [Birkhed and Heintze, 1989] and the protein buffer [Bardow et al., 2008], all acting at different $\mathrm{pH}$ ranges and affecting $\mathrm{pH}$ and buffering capacity. Generally, the values of $\mathrm{pH}$ and buffering capacity were comparably high in the present study. Maybe this was caused by freezing the saliva intermittently before measuring $\mathrm{pH}$. Freezing can lead to a loss of $\mathrm{CO}_{2}$, which in turn results in a shift of $\mathrm{pH}$ into the alkaline direction [Bardow et al., 2000]. However, only an analysis of frozen saliva was possible, since the participants collected the saliva directly and $30 \mathrm{~min}$ after vomiting at home and froze it. In order 
to ensure comparability between all types of saliva, frozen saliva has been analysed. In the past, it was postulated that the protein buffer is of low relevance [Lilienthal, 1955]. Recent studies, however, have shown that the protein buffering system is of considerable importance [Lamanda et al., 2007]. In particular, lysozyme and amylase seem to be of interest [Lamanda et al., 2007]. In the present study, slight changes in amylase and lysozyme activities were found. Even if no conclusions can be drawn from changes in activities with respect to the amount of proteins present in the saliva, a possible general shift in protein composition might have an impact on buffering capacity as all proteins show a buffering potential at different $\mathrm{pH}$ ranges. These changes can also be induced by the activation of the oesophago-salivary reflex: acidification of the oesophagus with $\mathrm{HCl}$ leads to an increase in salivary secretion [Shafik et al., 2005] and to a higher release of neutral and acidic mucins with the saliva [Sarosiek et al., 1994]. This mucin secretion is even enhanced by the combined stimulation with $\mathrm{HCl}$ and pepsin [Sarosiek et al., 1994]. All these changes induced by vomiting can possibly lead to a change in relative protein content with a possible impact on buffering capacity.

In conclusion, several pronounced changes in enzymatic activity were found in patients suffering from bulimia and dental erosion. The reason for these differences in enzymatic activity between both bulimic groups is not clear and should be elucidated in further studies. However, it can be concluded that the proteolytic activity of oral fluids contributes considerably to the formation and progression of dental erosion, probably by both the degradation of the demineralized organic structures of dentine and the weakening of the protective effects of the pellicle. Additionally, the buffering capacity is changed in patients with bulimia nervosa and dental erosion, possibly as a result of changes in the protein composition of saliva, however, with an unknown impact on the onset and progression of erosion. Accordingly, new strategies in the prevention of dental erosion should consider the inactivation of proteases and peptidases. This applies not only to the MMPs of the dentine but also to the free enzymes in the oral fluids.

\section{Acknowledgement}

We would like to thank the DGZMK (Deutsche Gesellschaft für Zahn-, Mund- und Kieferheilkunde) for supporting the study.

\section{Disclosure Statement}

The authors state that there is no conflict of interest.

\section{References}

Apajalathi S, Sorsa T, Railavo S, Ingman T: The in vivo levels of matrix metalloproteinase-1 and - 8 in gingival crevicular fluid during initial orthodontic tooth movement. J Dent Res 2003;82:1018-1022.

Bardow A, Lagerlöf F, Nauntofte B, Tenovuo J: The role of saliva; in Fejerskov O, Kidd E, Nyvad B, Baelum V (eds): Dental Caries. The Disease and Its Clinical Management. Oxford, Blackwell Munksgaard, 2008, pp 189208.

Bardow A, Moe D, Nyvad B, Nauntofte B: The buffer capacity and buffer systems of human whole saliva measured without loss of $\mathrm{CO}_{2}$. Arch Oral Biol 2000;45:1-12.

Bartlett DW, Coward PY: Comparison of the erosive potential of gastric juice and a carbonated drink in vitro. J Oral Rehabil 2001; 28:1045-1047.

Birkhed D, Heintze U: Salivary secretion rate, buffer capacity, and $\mathrm{pH}$; in Tenovuo JO (ed): Human Saliva: Clinical Chemistry and Microbiology. Boca Raton, CRC Press, 1989, vol 1 , pp 25-73.

Davis GE: Identification of an abundant latent 94-kDa gelatin-degrading metalloprotease in human saliva which is activated by acid exposure: implications for a role in digestion of collagenous proteins. Arch Biochem Biophys 1991;286:551-554.

DenBesten PK, Punzi JS, Li W: Purification and sequencing of a 21 and $25 \mathrm{kDa}$ bovine enamel metalloproteinase. Eur J Oral Sci 1998;106: 345-349.

Descamps FJ, Martens E, Ballaux F, Geboes K, Opdenakker G: In vivo activation of gelatinase B/MMP-9 by trypsin in acute pancreatitis is a permissive factor in streptozotocin-induced diabetes. J Pathol 2004;204:555-561.

Frydrych AM, Davies GR, McDermott BM: Eating disorders and oral health: a review of the literature. Aust Dent J 2005;50:6-15.

Furuyama M, Koshika S, Kitamura Y, Nakayama Y: Trypsin-like protease and glucose-6phosphate dehydrogenase in the human submandibular salivary gland. Arch Oral Biol 1987;32:761-762.

Ganss C, Hardt M, Blazek D, Klimek J, Schlueter $\mathrm{N}$ : Effects of toothbrushing force on the mineral content and demineralized organic matrix of eroded dentine. Eur J Oral Sci 2009; 117:255-260.
Ganss C, Hardt M, Lussi A, Cocks A-K, Klimek J, Schlueter N: Mechanism of action of tincontaining fluoride solutions as anti-erosive agents in dentine - an in vitro tin-uptake, tissue loss and scanning electron microscopy study. Eur J Oral Sci 2010;118:376-384.

Ganss C, Klimek J, Starck C: Quantitative analysis of the impact of the organic matrix on the fluoride effect on erosion progression in human dentine using longitudinal microradiography. Arch Oral Biol 2004;49:931-935.

Ganss C, Lussi A: Diagnosis of erosive tooth wear; in Lussi A (ed): Dental Erosion: From Diagnosis to Therapy. Monogr Oral Sci. Basel, Karger, 2006, pp 32-43.

Garant PR: Dentin: Oral Cells and Tissues. Berlin, Quintessence Publishing, 2003, pp 25-52.

Gonçalves R, Soares S, Mateus N, de Freitas V: Inhibition of trypsin by condensed tannins and wine. J Agric Food Chem 2007;55:75967601.

Hannig C, Attin T, Hannig M, Henze E, Brinkmann K, Zech R: Immobilisation and activity of human alpha-amylase in the acquired enamel pellicle. Arch Oral Biol 2004a;49: 469-475. 
Hannig C, Becker K, Häusler N, Hoth-Hannig W, Attin T, Hannig M: Protective effect of the in situ pellicle on dentin erosion - an ex vivo pilot study. Arch Oral Biol 2007;52:444449.

Hannig C, Hannig M, Attin T: Enzymes in the acquired enamel pellicle. Eur J Oral Sci 2005; 113:1-12.

Hannig C, Spitzmüller B, Al-Ahmad A, Hannig M: Effects of Cistus-tea on bacterial colonization and enzyme activities of the in situ pellicle. J Dent 2008a;36:540-545.

Hannig C, Spitzmüller B, Hannig M: Characterisation of lysozyme activity in the in situ pellicle using a fluorimetric assay. Clin Oral Invest 2009;13:15-21.

Hannig C, Spitzmüller B, Knausenberger S, Hoth-Hannig W, Hellwig E, Hannig M: Detection and activity of peroxidase in the in situ formed enamel pellicle. Arch Oral Biol 2008b;53:849-858.

Hannig C, Spitzmüller B, Miller M, Hellwig E, Hannig M: Intrinsic enzymatic crosslinking and maturation of the in situ pellicle. Arch Oral Biol 2008c;53:416-422.

Hannig M, Balz M: Protective properties of salivary pellicles from two different intraoral sites on enamel erosion. Caries Res 2001;35: 142-148.

Hannig M, Fiebiger M, Güntzer M, Döbert A, Zimehl R, Nekrashevych Y: Protective effect of the in situ formed short-term salivary pellicle. Arch Oral Biol 2004b;49:903-910.

Hannig M, Joiner A: The structure, function and properties of the acquired pellicle. Monogr Oral Sci 2006;19:29-64.

Hara AT, Lussi A, Zero DT: Biological factors; in Lussi A (ed): Dental Erosion - From Diagnosis to Therapy. Monogr Oral Sci. Basel, Karger, 2006, vol 20, pp 88-99.

Ingman T, Tervahartiala T, Ding Y, Tschesche $\mathrm{H}$, Haerian A, Kinane DF, Konttinen YT, Sorsa T: Matrix metalloproteinases and their inhibitors in gingival crevicular fluid and saliva of periodontitis patients. J Clin Periodontol 1996;23:1127-1132.

Joiner A, Schwarz A, Philpotts CJ, Cox TF, Huber $\mathrm{K}$, Hannig M: The protective nature of pellicle towards toothpaste abrasion on enamel and dentine. J Dent 2008;36:360368.

Kim TH, Lee KJ, Yeo M, Kim DK, Cho SW: Pepsin detection in the sputum/saliva for the diagnosis of gastroesophageal reflux disease in patients with clinically suspected atypical gastroesophageal reflux disease symptoms. Digestion 2008;77:201-206.

Kleter GA, Damen JJ, Everts V, Niehof J, ten Cate JM: The influence of the organic matrix on demineralization of bovine root dentin in vitro. J Dent Res 1994;73:1523-1529.

Lamanda A, Cheaib Z, Turgut MD, Lussi A: Protein buffering in model systems and in whole human saliva. PLoS One 2007;2:e263.

Lilienthal B: An analysis of the buffer systems in saliva. J Dent Res 1955;34:516-530.
Lindstad RI, Sylte I, Mikalsen SO, Seglen PO, Berg E, Winberg JO: Pancreatic trypsin activates human promatrix metalloproteinase-2. J Mol Biol 2005;350:682-698.

Lussi A, Jaeggi T: Erosion - diagnosis and risk factors. Clin Oral Invest 2008;12:S5-S13.

Lussi A, Schlueter N, Rakhmatullina E, Ganss C: Dental erosion - an overview with emphasis on chemical and histopathological aspects. Caries Res 2011;45(suppl 1):2-12.

Maeda H: A new lysozyme assay based on fluorescence polarization or fluorescence intensity utilizing a fluorescent peptidoglycan substrate. J Biochem 1980;88:1185-1191.

Mäkelä M, Salo T, Uitto VJ, Larjava H: Matrix metalloproteinases (MMP-2 and MMP-9) of the oral cavity: cellular origin and relationship to periodontal status. J Dent Res 1994; 73:1397-1406.

Moon PC, Weaver J, Brooks CN: Review of matrix metalloproteinases' effect on the hybrid dentin bond layer stability and chlorhexidine clinical use to prevent bond failure. Open Dent J 2010;4:147-152.

Morishita Y, Iinuma Y, Nakashima N, Majima K, Mzuguchi K, Kawamura Y: Total and pancreatic amylase measured with 2-chloro-4nitrophenyl-4-O-beta-D-galactopyranosylmaltoside. Clin Chem 2000;46:928-933.

Nascimento FD, Minciotti CL, Geraldeli S, Carrilho MR, Pashley DH, Tay FR, Nader HB, Salo T, Tjaderhane L, Tersariol IL: Cysteine cathepsins in human carious dentin. J Dent Res 2011;90:506-511.

Nekrashevych Y, Hannig M, Stosser L: Assessment of enamel erosion and protective effect of salivary pellicle by surface roughness analysis and scanning electron microscopy. Oral Health Prev Dent 2004;2:5-11.

Proctor GB, Chan KM: A fluorometric assay of peroxidase activity utilizing $2^{\prime}, 7^{\prime}$-dichlorofluorescein with thiocyanate: application to the study of salivary secretion. J Biochem Biophys Methods 1994;28:329-336.

Richter C, Tanaka T, Yada RY: Mechanism of activation of the gastric aspartic proteinases: pepsinogen, progastricsin and prochymosin. Biochem J 1998;335:481-490.

Robb ND, Smith BG, Geidrys LE: The distribution of erosion in the dentitions of patients with eating disorders. Br Dent J 1995;178: 171-175.

Sarosiek J, Rourk RM, Piascik R, Namiot Z, Hetzel DP, McCallum RW: The effect of esophageal mechanical and chemical stimuli on salivary mucin secretion in healthy individuals. Am J Med Sci 1994;308:23-31.

Sas R, Dawes C: The intra-oral distribution of unstimulated and chewing-gum-stimulated parotid saliva. Arch Oral Biol 1997;42:469474.

Scheutzel P, Gerlach U: Alpha-amylase isoenzymes in serum and saliva of patients with anorexia and bulimia nervosa. Z Gastroenterol 1991;29:339-345.
Schlueter N, Ganss C, Hardt M, Schegietz D, Klimek J: Effect of pepsin on erosive tissue loss and the efficacy of fluoridation measures in dentine in vitro. Acta Odontol Scand 2007;65:298-305.

Schlueter N, Hardt M, Klimek J, Ganss C: Influence of the digestive enzymes trypsin and pepsin in vitro on the progression of erosion in dentine. Arch Oral Biol 2010;55:294-299.

Shafik A, El Sibai O, Shafik AA, Mostafa R: Effect of topical esophageal acidification on salivary secretion: identification of the mechanism of action. J Gastroenterol Hepatol 2005;20:1935-1939.

Sorsa T, Tjäderhane L, Salo T: Matrix metalloproteinases (MMPs) in oral diseases. Oral Dis $2004 ; 10: 311-318$.

Stuchell RN, Mandel ID: A comparative study of salivary lysozyme in caries-resistant and caries-susceptible adults. J Dent Res 1983;62: 552-554.

Tatsuguchi A, Fukuda Y, Ishizaki M, Yamanaka $\mathrm{N}$ : Localization of matrix metalloproteinases and tissue inhibitor of metalloproteinases-2 in normal human and rabbit stomachs. Digestion 1999;60:246-254.

Tjäderhane L, Larjava H, Sorsa T, Uitto VJ, Larmas M, Salo T: The activation and function of host matrix metalloproteinases in dentin matrix breakdown in caries lesions. J Dent Res 1998;77:1622-1629.

Uitto VJ: Human gingival proteases. I: Extraction and preliminary characterization of trypsin-like and elastase-like enzymes. J Periodontal Res 1987;22:58-63.

van Strijp AJ, Jansen DC, DeGroot J, ten Cate JM, Everts V: Host-derived proteinases and degradation of dentine collagen in situ. Caries Res 2003;37:58-65.

Veerman EC, van den Keybus PA, Vissink A, Nieuw Amerongen AV: Human glandular salivas: their separate collection and analysis. Eur J Oral Sci 1996;104:346-352.

Vilen ST, Nyberg P, Hukkanen M, Sutinen M, Ylipalosaari M, Bjartell A, Paju A, Haaparanta V, Stenman UH, Sorsa T, Salo T: Intracellular co-localization of trypsin-2 and matrix metalloprotease-9: possible proteolytic cascade of trypsin-2, MMP-9 and enterokinase in carcinoma. Exp Cell Res 2008;314:914926.

Vray B, Hoebeke J, Saint-Guillain M, Leloup R, Strosberg AD: A new quantitative fluorimetric assay for phagocytosis of bacteria. Scand J Immunol 1980;11:147-153.

Vuotila T, Ylikontiola L, Sorsa T, Luoto H, Hanemaaijer R, Salo T, Tjäderhane L: The relationship between MMPs and $\mathrm{pH}$ in whole saliva of radiated head and neck cancer patients. J Oral Pathol Med 2002;31:329-338.

Zheng X, Pan H, Wang Z, Chen H: Real-time enzymatic degradation of human dentin collagen fibrils exposed to exogenous collagenase: an AFM study in situ. J Microsc 2011; 241:162-170. 